\title{
Fungal microbiota in seeds, seedlings and mature plants of raspberry (Rubus ideaus L.)
}

\author{
Wojciech Wysoczański • Ewa Wegrzyn • Marlena \\ Lembicz • Bogdan Jaroszewicz
}

Accepted: 11 August 2021

(C) The Author(s) 2021

\begin{abstract}
Presently, there is an intensive search for fungal endophytes to be used in agriculture for the protection and condition improvement of plants and in medicine. We screened for the presence of endophytes in raspberry, which occurs naturally in the Białowieża Forest. The fungal isolates representative of each morphotype were analysed using the molecular markers ITS1 and ITS2. In total, we found 34 taxa of endophytic fungi. The majority were potential pathogens. As many as 27 taxa were found in the leaves of mature plants. No fungi could be isolated from the surface sterilized seeds obtained from these plants. Seedlings were grown from the seeds deposited in the soil seed bank in the Białowieża Geobotanical Station of the University of Warsaw in Białowieża. 8 taxa of endophytic fungi were found in seedlings. It could be due to a possibility of seed infection with these endophytes in soil conditions.
\end{abstract}

Keywords Białowieża Forest · Fungal endophytes . Molecular detection $\cdot$ Raspberry $\cdot$ Vertical transfer

\footnotetext{
W. Wysoczański · E. Węgrzyn · M. Lembicz $(\bowtie)$

Department of Systematic and Environmental Botany, Faculty of Biology, Adam Mickiewicz University, Uniwersytetu

Poznańskiego 6, 61-614 Poznań, Poland

e-mail: lembicz@amu.edu.pl

B. Jaroszewicz

Białowieża Geobotanical Station, Faculty of Biology, University of Warsaw, Sportowa 19, 17-230, Białowieża, Poland
}

\section{Introduction}

Fungal endophytes are endosymbionts that occur in almost every plant (Petrini, 1986). Their number and taxonomical diversity depend on many factors, including the species, genotype, developmental stage and living environment of the host plant (Cheplick \& Faeth, 2009). Effects of interactions between plants and endophytic fungi are also diverse. There is a spectrum of physiological and ecological effects, from positive to adverse, even for the same fungal taxon (Saikkonen et al., 1998; Faeth \& Fagan, 2002).

Currently, there is a search for fungal endosymbionts that could improve condition of plants through increasing their biomass and seed production and protect them against pathogenic parasites that generate losses in agriculture (e.g., Rodriguez et al., 2009; Turner et al., 2013). Such endosymbionts may be an alternative for chemical agents used against plant parasites. Endophytic bioinoculants have been already developed that increase the biomass of plants and protect them against pathogens (Kauppinen et al., 2016). Furthermore, there is a search for fungal endophytes that produce chemical substances useful in medicine (e.g., Strobel \& Daisy, 2003; Egan et al., 2016; Pelo et al., 2020).

However, the application of symbiotically modified organisms in agriculture may have some downsides and should be treated with caution. Before an agricultural plant is subjected to inoculation, it must be ensured that the effects of such an interaction are safe in the longterm. From the evolutionary point of view, achieving such certainty is difficult. Symbiosis is the type of 
interaction in which the compatibility of both partners may change. The strains of endophytes we currently consider safe and introduce into plants may become pathogenic over time. We do not know the effects of mutation accumulation in the genetic material of these organisms. However, plants consumed by humans, such as crop plants and plants with confirmed medicinal properties, should be decidedly checked for endophyte presence.

The aim of this study was to check for the presence and taxonomical identification of fungal endophytes in raspberry ( $R$. idaeus L.). We were interested to determine whether the number of species and taxonomical composition of fungal microbiota depend on the developmental stage of raspberry. Thus, we decided to conduct the endophyte detection not only in leaves but also in seeds originating from the same individuals. This is the first report of the occurrence of endophytic fungi in the different developmental stages of raspberry - in seeds and mature plants from forest and in seedlings obtained from seeds deposited in the soil seed bank. Raspberry is a fairly common plant in Poland that is cultivated as a fruit shrub. Poland is a leading producer of raspberry fruits both in Europe and in the world (Baranowska et al., 2015). Vegetative (leaves) and generative (seeds) organs of raspberry are widely used for medical and nutritional purposes and in cosmetology (Kalinowska et al., 2017).

\section{Materials and methods}

\section{Material origin}

Fungal microbiota of raspberry (Rubus ideaus L.) were studied in six localities in the Białowieża Forest (Fig. 1). The presence of fungi was checked in the juvenile stages of plants (seeds) and in the mature stage (leaves). Leaves and fruits with seeds were collected directly in the field. Seedlings were grown from the seeds deposited in the soil seed bank in the Białowieża Geobotanical Station of the University of Warsaw in Białowieża. Seedlings were grown directly from the soil collected in the forest. Seeds were not extracted from the soil sample but allowed to germinate in the greenhouse together with seedlings of all other species present there. All seedlings for analysis were collected at the same date, and their age was between 5 and 14 days. The collected leaves and fruit, as well as the grown seedlings were transported to the laboratory of the Department of Systematic and Environmental Botany of the Adam Mickiewicz University in Poznań. The material was healthy and prepared in the same year in 2019.

\section{Cultivation and passage of fungi}

Before the establishment of the in vitro culture of fungi, the plant material (seeds and both seedlings and mature plant leaves) was subjected to sterilization to exclude externally occurring fungi (Górzyńska et al., 2019). The presence of fungal endophytes was checked in 180 seeds ( 30 seeds per site), 24 seedlings and 60 leaves (10 leaves per site). This number of seedlings was successfully grown from seeds obtained from a seed bank. The seeds were subjected to surface sterilization with $4.5 \% \mathrm{NaOCl}$ for $60 \mathrm{~min}$, with distilled water for rinsing. The seedlings and leaf fragments were subjected also to surface sterilization $(75 \%$ ethanol $30 \mathrm{~s}, 5 \% \mathrm{NaOCl} 3.5 \mathrm{~min}, 75 \%$ ethanol $15 \mathrm{~s}$, with distilled water for rinsing). Then, seedlings and leaves were cut into small pieces. Next, the seeds and plant fragments were placed in Petri dishes with Potato Dextrose Agar (PDA) medium containing antibiotics (chloramphenicol, $100 \mathrm{mg}$ / L). In total, 18 dishes for seeds (10 seeds per dish), 24 for seedlings ( 1 seedling per dish) and 60 for mature plants (1 leaf per dish) were prepared. The plates were placed in dark in an incubator at $25^{\circ} \mathrm{C}$. They were observed every day, and emerging fungi were successively transplanted to new, fresh plates. For the identification of endophytes, the fungal isolates were grouped into morphotypes based on macroscopic characteristics, such as the appearance and colour of the mycelium. Then, isolates representative of each morphotype were analysed using molecular methods.

Molecular identification

The DNA was isolated using a Quick-DNA Fungal/ Bacterial Miniprep Kit (Zymo Research, USA) according to the manufacturer's protocol and was stored at $-20{ }^{\circ} \mathrm{C}$. A pair of primers, ITS1F (Gardes \& Bruns, 1993) and ITS4 (White et al., 1990), was used to amplify the ribosomal cassette, which consisted of SSU, ITS1, 5.8S, ITS2 and LSU rDNA. The PCR was conducted according to the protocol used in another research (Wegrzyn et al., 2020). The PCR products were purified using alkaline phosphatase and exonuclease I and directly cycle-sequenced with ABI BigDye Terminator ver. 3.1 (Applied Biosystems, USA). The obtained sequences were edited using Chromas (www. technelysium.com.au) software and were submitted to 
Fig. 1 Localities of material collection (leaves and fruits with seeds) of raspberry (Rubus ideaus) in the Bialowieża Forest, Poland. Seedlings were raised in the experimental greenhouse of the Białowieża Geobotanical Station (University of Warsaw) from seeds contained in soil samples collected at sampling sites

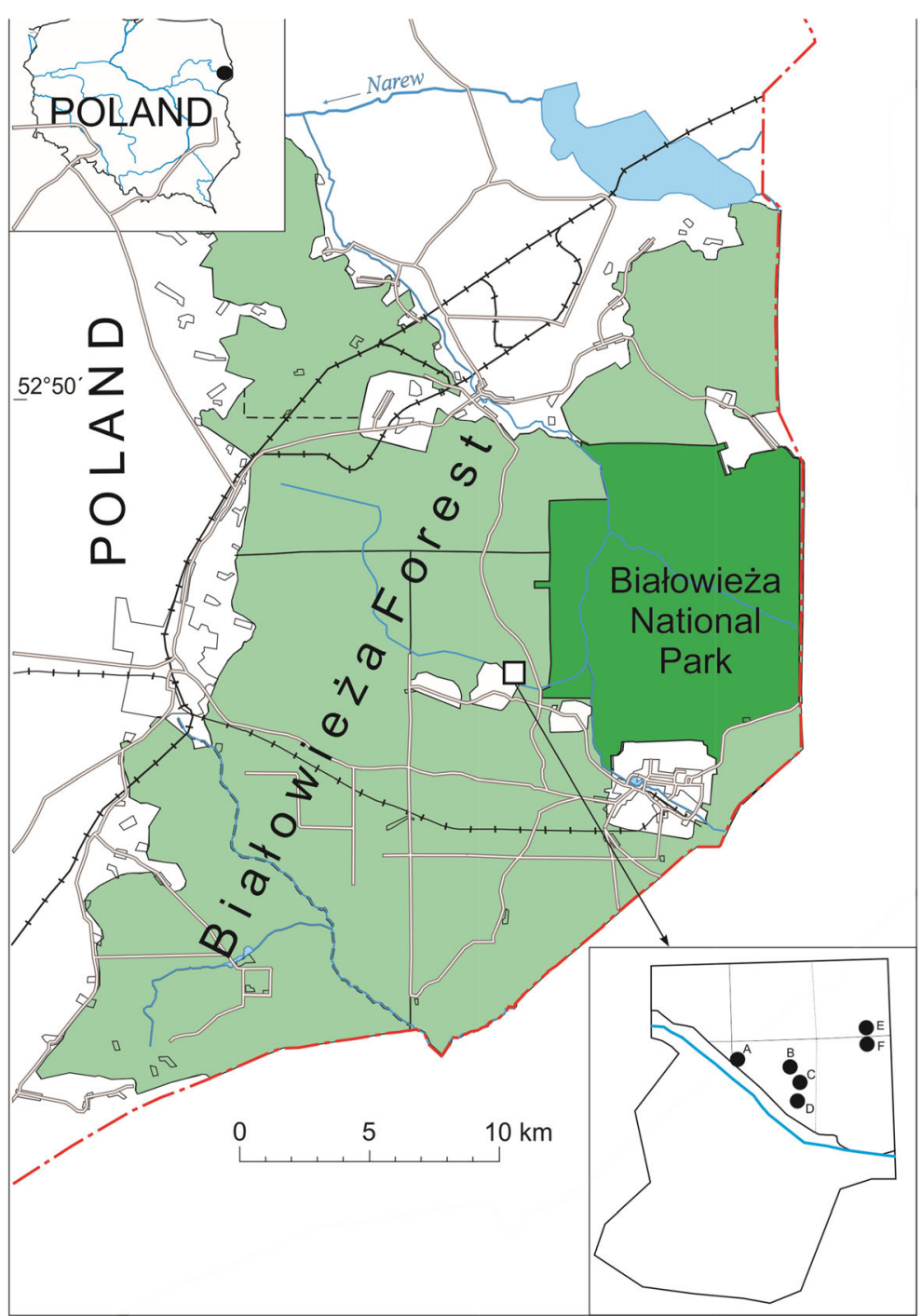

GenBank (Table 1). Finally, the sequences were compared to those published in the European Molecular Biology Laboratory (EMBL) nucleotide databases and in the NCBI (www.ncbi.nlm.nih.gov) databases using BLAST (Altschul et al., 1990). A positive identification of a species was confirmed if $\geq 98 \%$ of the ITS region sequence identity was shared with the reference sequence from the databases.

\section{Results and discussion}

There were no endophytic fungi found in 180 seeds extracted from fresh fruits of raspberry (Rubus ideaus). The highest number of fungi (27 taxa) was identified in the leaves of mature plants, while 8 taxa were found in the seedlings (Table 1). In total, 34 endophytic fungi were recorded in the seedlings and leaves of mature plants. The only species that was present in both these developmental stages was pathogen species Botrytis cinerea. In both the mature plants and seedlings, there were also representatives of the genus Penicillium: in the former, Penicillium chrysogenum was identified, while Penicillium cosmopolitanum was found in the latter. In the mature plants, three species of Alternaria were identified, A. alternata, Alternaria infectoria and A. tenuissima, three species of Colletotrichum, and two each from the genera Cladosporium and Epicoccum. Other genera were represented by single species. 
Table 1 Endophytic fungal species identified in Rubus ideaus seedlings and mature plants

\begin{tabular}{|c|c|c|c|c|c|c|c|}
\hline \multirow[t]{2}{*}{ No. } & \multirow[t]{2}{*}{ Fungal taxa } & \multirow[t]{2}{*}{ seedlings } & \multirow[t]{2}{*}{ mature plants } & \multicolumn{3}{|c|}{ BLAST match sequence } & \multirow[t]{2}{*}{ GenBank no. } \\
\hline & & & & Accession no. & Similarity $(\%)$ & Coverage (\%) & \\
\hline 1 & Acremonium sclerotigenum & - & + & MH859618 & 99.8 & 99 & MT573463 \\
\hline 2 & A. alternata & - & + & КT345696 & 100 & 100 & MT573464 \\
\hline 3 & Alternaria infectoria & - & + & MK461063 & 99.50 & 100 & MT573465 \\
\hline 4 & A. tenuissima & - & + & MK675103 & 100 & 99 & MT573466 \\
\hline 5 & Apiotrichum porosum & + & - & KY558352 & 99.1 & 100 & MT573467 \\
\hline 6 & Aureobasidium pullulans & - & + & EF690466 & 100 & 99 & MT573468 \\
\hline 7 & Bjerkandera adusta & - & + & MH857085 & 99.8 & 99 & MT573469 \\
\hline 8 & Botrytis cinerea & + & + & KU992700 & 99.50 & 100 & MT573470 \\
\hline 9 & Cladosporium allicinum & - & + & MH857286 & 100 & 100 & MT573471 \\
\hline 10 & Cladosporium cladosporioides & - & + & MH863979 & 99.6 & 100 & MT573472 \\
\hline 11 & Colletotrichum dematium & - & + & MG978337 & 100 & 100 & MT573473 \\
\hline 12 & Colletotrichum salicis & - & + & MT068551 & 99 & 99 & MT573474 \\
\hline 13 & Colletotrichum truncatum & - & + & MH248046 & 100 & 99 & MT573475 \\
\hline 14 & Coniochaeta velutina & - & + & MN341294 & 99.3 & 99 & MT573476 \\
\hline 15 & Cytospora cedri & - & + & MN764316 & 98.3 & 94 & MT573477 \\
\hline 16 & Diaporthe eres & - & + & MK352454 & 99.8 & 99 & MT573478 \\
\hline 17 & Epicoccum layuense & - & + & MN396392 & 100 & 99 & MT573479 \\
\hline 18 & Epicoccum nigrum & - & + & MF509753 & 99.6 & 100 & MT573480 \\
\hline 19 & Hypoxylon fragiforme & - & + & MG098276 & 99.8 & 100 & MT573481 \\
\hline 20 & Ilyonectria crassa & + & - & MT294410 & 99.6 & 100 & MT573482 \\
\hline 21 & Jackrogersella multiformis & - & + & MK351664 & 99.8 & 98 & MT573483 \\
\hline 22 & Melanconis stilbostoma & - & + & AY577811 & 99.7 & 99 & MT573484 \\
\hline 23 & Mucor hiemalis & + & - & MF615076 & 99.7 & 99 & MT573485 \\
\hline 24 & Nemania serpens & - & + & EF155504 & 99.8 & 99 & MT573486 \\
\hline 25 & Paraphaeosphaeria neglecta & - & + & MG098298 & 99.5 & 97 & MT573487 \\
\hline 26 & Penicillium chrysogenum & - & + & KT963794 & 100 & 99 & MT573488 \\
\hline 27 & Penicillium cosmopolitanum & + & - & JN617682 & 99.8 & 100 & MT573489 \\
\hline 28 & Preussia minima & - & + & KU713051 & 99.5 & 99 & MT573490 \\
\hline 29 & Pseudogymnoascus pannorum & + & - & MH864434 & 98.6 & 99 & MT573491 \\
\hline 30 & Schizophyllum commune & - & + & KP326577 & 99.5 & 99 & MT573492 \\
\hline 31 & Umbelopsis isabellina & + & - & MF417265 & 98.7 & 98 & MT573493 \\
\hline 32 & U. maydis & - & + & MH855355 & 100 & 99 & MT573494 \\
\hline 33 & Varicosporium elodeae & + & - & JX981463 & 99.3 & 100 & MT573495 \\
\hline 34 & Xenodidymella applanata & - & + & MH855770 & 100 & 99 & MT573496 \\
\hline
\end{tabular}

A plant may be inhabited by a consortium of fungal microbiota (Shade et al., 2017; Vannier et al., 2018). We revealed that the number of species and taxonomical diversity of such microbiota in raspberry are different in seeds, seedlings, and mature plants. The highest number of fungi - 27 taxa of 34 in total, was present in the mature plants, followed by seedlings ( 8 taxa), while the seeds were free of endophytes. It is possible that the low number of identified fungi in seedlings is caused by the fact that detection was performed on a smaller sample. The identified taxa represent mainly non-systemic fungi of Ascomycota.

Non-systemic endophytes occur in different groups of plants (e.g., Ruotsalainen et al., 2002; Rodriguez et al., 
2009; Loro et al., 2012). Their activity in plants is poorly known, particularly their effect on plant defence mechanisms (Saikkonen et al., 1998; Rodriguez \& Redman, 2008; Cook et al., 2009). The majority of endophytes identified by us in raspberry are regarded as plant pathogens, particularly such taxa as Alternaria spp. or Botrytis cinerea. A. alternata is mainly known as a parasite. It contains seven pathogenic variants (pathotypes) that produce the host-specific toxins and, as a result, may cause disease in different hosts (Hatta et al., 2002). A. infectoria had been already previously regarded as an endophyte (Martin \& Dombrowski, 2015). This species also occurs in the tissues of apple tree buds. During flower and fruit development, it metamorphoses into a pathogenic form that causes core rot (Serdani et al., 1998). Moslemi et al. (2017) found a new pathogen in $T$. cinerariifolium that causes double-sided leaf necrosis and was identified as A. infectoria. B. cinerea promotes grey mould disease and may attack over 200 species of host plants (Staats et al., 2005). Species of the genus Colletotrichum are also plant pathogens that cause anthracnose diseases (Freeman et al., 1998).

The activity of fungal microbiota in plants is an effect of interactions between individual organisms. It is possible to evaluate the activity of a single fungal taxon in laboratory conditions in plants experimentally devoid of their microbiota. However, the activity of the same fungus involved in interactions with other fungi that inhabit a plant in natural conditions may be different. A single taxon may have a negative effect on its host, but in the presence of another taxon, this effect may be reduced or eliminated. Some endophytes may also stimulate other endophytes to produce chemical compounds that affect the plant defence system (e.g., Markert et al., 2008).

We found that the taxonomical composition of endophytic fungal microbiota changes throughout the plant's life. Some taxa, present in raspberry in the seedling stage (e.g., Apiotrichum porosum or Mucor hiemalis), are absent from the leaves of mature plants and vice versa. However, the mature plants were not cultivated from the cohort of analysed seedlings, thus, the observed differences may be effect of high spatial diversity of soil fungal communities. Particularly interesting is the fact that there were no fungal endophytes in the seeds sampled directly from fruits of these mature plants. Vaughan et al. (1993) reported the presence of many chemical substances in mature raspberry fruits that inhibit the development of fungi, including such species as A. alternata, B. cinerea and Coletotrichum gloeosporioides. These substances may be the cause of fungal endophyte absence from the seeds collected from raspberry fruits, which breaks vertical transmission of endophytes from mature plants to seedlings of the next generation via seeds. Vertical transmission through host seeds is a mechanism that enables fungal spread within the plant population; thus, it ensures the continuance of endophytes in populations of a given species (Hodgson et al., 2014; Wiewióra et al., 2015). Our results confirm previous studies reporting that the majority of non-systemic fungal endophytes are not transmitted through seeds (Márquez et al., 2012). Thus, the question arises: how did the identified fungal endophytes infect the studied raspberry seedlings? We presume that seed infection took place when the seeds were deposited in the soil. We think this is the case because in the analysis of fungal microbiota, we used seedlings that originated from the seeds deposited in the soil seed bank. We will test this hypothesis in our future research.

Acknowledgements We thank Elżbieta Obarska for comments on our manuscript. We wish to thank the reviewers for their comments.

Funding This work was supported by the statutory funds of the Department of Systematic and Environmental Botany of Adam Mickiewicz University in Poznań, Project No. 0200000000/604/ 505000/BN002018/S/PB/0-25. Samples of Rubus idaeus were collected in the framework of the Dr. FOREST project no. 2019/31/Z/NZ8/04032, funded by the National Science Centre, Poland under BiodivERsA3 programme.

\section{Declarations}

Informed consent Not applicable.

Human participants and/or animals Not applicable.

Conflict of interest All authors declare that they have no conflict of interest.

Open Access This article is licensed under a Creative Commons Attribution 4.0 International License, which permits use, sharing, adaptation, distribution and reproduction in any medium or format, as long as you give appropriate credit to the original author(s) and the source, provide a link to the Creative Commons licence, and indicate if changes were made. The images or other third party material in this article are included in the article's Creative Commons licence, unless indicated otherwise in a credit line to the material. If material is not included in the article's Creative Commons licence and your intended use is not permitted by statutory regulation or exceeds the permitted use, you will need to obtain permission directly from the copyright holder. To view a copy of this licence, visit http://creativecommons.org/licenses/by/4.0/. 


\section{References}

Altschul, S., Gish, W., Miller, W., Myers, E., \& Lipman, D. (1990). Basic local alignment search tool. Journal of Molecular Biology, 215, 403-410.

Baranowska, A., Radwańska, K., Zarzecka, K., Gugała, M., \& Mystkowska, I. (2015). Właściwości prozdrowotne owoców maliny właściwej (Rubus idaeus L.). Problemy Higieny $i$ Epidemiologii, 96(2), 406-409.

Cheplick, G. P. \& Faeth, S. H. (2009). Ecology and evolution of the grass - Endophyte Symbiosis. Oxford University press. 240 ss.

Cook, D., Gardner, D. R., Welch, K. D., Roper, J. M., Ralphs, M. H., \& Green, B. T. (2009). Quantitative PCR method to measure the fungal endophyte in locoweeds. Journal of Agricultural and Food Chemistry, 57(14), 6050-6054.

Egan, J. M., Kaur, A., Raja, H. A., Kellogg, J. J., Oberlies, N. H., \& Cech, N. B. (2016). Antimicrobial fungal endophytes from the botanical medicine goldenseal (Hydrastis canadensis). Phytochemistry Letters, 17, 219-225.

Faeth, S., \& Fagan, W. F. (2002). Fungal endophytes: Common host plant symbionts but uncommon mutualists. Integrative and Comparative Biology, 42(2), 360-368.

Freeman, S., Katan, T., \& Shabi, E. (1998). Characterization of Colletotrichum species responsible for anthracnose diseases of various fruits. Plant Disease, 82(6), 596-605.

Gardens, M., \& Bruns, T. D. (1993). ITS primers with enhanced specificity for basidiomycetes - Application to the identification of mycorrhizae and rusts. Molecular Ecology, 2, 113-118.

Górzyńska, K., Wegrzyn, E., Sandecki, R., \& Lembicz, M. (2019). Endophytic fungi and latent pathogens in the sedge Carex secalina (Cyperaceae), a critically endangered species in Europe. Plant Protection Science, 55, 102-108.

Hatta, R., Ito, K., Hosaki, Y., Tanaka, T., Tanaka, A., Yamamoto, M., \& Tsuge, T. (2002). A conditionally dispensable chromosome controls host-specific pathogenicity in the fungal plant pathogen Alternaria alternata. Genetics, 161(1), 59-70.

Hodgson, S., de Cates, C., Hodgson, J., Morley, N., Sutton, B. C., \& Gange, A. C. (2014). Vertical transmission of fungal endophytes is widespread in forbs. Ecology and Evolution, 4(8), 1199-1208.

Kalinowska, N., Nowak, I., \& Zielińska, A. (2017). Właściwości oleju z pestek malin wykorzystywane w kosmetyce. Kosmetologia Estetyczna, 6(2), 121-123.

Kauppinen, M., Saikkonen, K., Helander, M., Pirttilä, A. M., \& Wäli, P. R. (2016). Epichloë grass endophytes in sustainable agriculture. Nature Plants, 2, 15224.

Loro, V. L., Jorge, M. B., da Silva, K. R., \& Wood, C. M. (2012). Oxidative stress parameters and antioxidant response to sublethal waterborne zinc in a euryhaline teleost Fundulus heteroclitus: Protective effects of salinity. Aquatic Toxicology, 110, 187-193.

Markert, A., Steffan, N., Ploss, K., Hellwig, S., Steiner, U., Drewke, C., \& Leistner, E. (2008). Biosynthesis and accumulation of ergoline alkaloids in a mutualistic association between Ipomoea asarifolia (Convolvulaceae) and a clavicipitalean fungus. Plant Physiology, 147(1), 296-305.

Márquez, S. S., Bills, G. F., Herrero, N., \& Zabalgogeazcoa, I. (2012). Non-systemic fungal endophytes of grasses. Fungal Ecology, 5(3), 289-297.

Martin, R., \& Dombrowski, J. (2015). Isolation and identification of fungal endophytes from grasses along the Oregon coast. American Journal of Plant Sciences, 6, 3216-3230.
Moslemi, A., Ades, P. K., Groom, T., Nicolas, M. E., \& Taylor, P. W. (2017). Alternaria infectoria and Stemphylium herbarum, two new pathogens of pyrethrum (Tanacetum cinerariifolium) in Australia. Australasian Plant Pathology, 46(1), 91-101.

Pelo, S., Mavumengwana, V., \& Green, E. (2020). Diversity and antimicrobial activity of Culturable fungal endophytes in Solanum mauritianum. International Journal of Environmental Research and Public Health, 17(2), 439.

Petrini, O. (1986). Taxonomy of endophytic fungi of aerial plant tissues. In N. J. Fokkema \& J. Van Den Heuvel (Eds.), Microbiology of Phyllosphere (pp. 175-187). UK: Cambridge.

Rodriguez, R., \& Redman, R. (2008). More than 400 million years of evolution and some plants still can't make it on their own: Plant stress tolerance via fungal symbiosis. Journal of Experimental Botany, 59(5), 1109-1114.

Rodriguez, R. J., White Jr., J. F., Arnold, A. E., \& Redman, A. R. A. (2009). Fungal endophytes: Diversity and functional roles. New Phytologist, 182(2), 314-330.

Ruotsalainen, A., Väre, H., \& Vestberg, M. (2002). Seasonality of root fungal colonization in low-alpine herbs. Mycorrhiza, 12(1), 29-36.

Saikkonen, K., Faeth, S. H., Helander, M., \& Sullivan, T. J. (1998). Fungal endophytes: A continuum of interactions with host plants. Annual Review of Ecology and Systematics, 29(1), 319-343.

Shade, A., Jacques, M. A., \& Barret, M. (2017). Ecological patterns of seed microbiome diversity, transmission, and assembly. Current Opinion in Microbiology, 37, 15-22.

Serdani, M., Crous, P. W., Holz, G., \& Petrini, O. (1998). Endophytic fungi associated with core rot of apples in South Africa, with specific reference to Alternaria species. Sydowia, 50, 257-271.

Staats, M., van Baarlen, P., \& van Kan, J. A. (2005). Molecular phylogeny of the plant pathogenic genus Botrytis and the evolution of host specificity. Molecular Biology and Evolution, 22(2), 333-346.

Strobel, G., \& Daisy, B. (2003). Bioprospecting for microbial endophytes and their natural products. Microbiology and Molecular Biology Reviews, 67(4), 491-502.

Turner, T. R., James, E. K., \& Poole, P. S. (2013). The plant microbiome. Genome Biology, 14, 1-10.

Vannier, N., Mony, C., Bittebiere, A.-K., Michon-Coudouel, S., Biget, M., \& Vandenkoornhuyse, P. (2018). A microorganisms' journey between plant generations. Microbiome, 6, 79.

Vaughn, S. F., Spencer, G. F., \& Shasha, B. S. (1993). Volatile compounds from raspberry and strawberry fruit inhibit postharvest decay fungi. Journal of Food Science, 58(4), 793-796.

Węgrzyn, E., Dominiak-Świgoń, M., Górzyńska, K., Chmiel, J., Świtalski, K., \& Lembicz, M. (2020). Fungal microbiota in the seeds of the clonal plant Iris sibirica - A threatened species in Europe. Sydowia, 72, 107-114.

White, T., Bruns, T., Lee, S., \& Taylor, J. (1990). Amplification and direct sequencing of fungal ribosomal RNA genes for phylogenetics. In M. Innis, D. Gelfand, J. Shinsky, \& T. White (Eds.), PCR protocols: A guide to methods and applications (pp. 315-322). USA: New York.

Wiewióra, B., Żurek, G., \& Pańka, D. (2015). Is the vertical transmission of Neotyphodium lolii in perennial ryegrass the only possible way to the spread of endophytes? Public Library of Science ONE, 10(2), e0117231. 